\title{
Health information technologies in Iran: Opportunities for development
}

\author{
Morteza Hemmat ${ }^{1}$, Haleh Ayatollahi*2, ${ }^{3}$, Mohammadreza Maleki ${ }^{3}$, Fatemeh Saghafi ${ }^{4}$ \\ Received: 12 Mar 2018 \\ Published: 30 Sep 2019
}

Abstract

Background: Health information technologies (HIT) have some benefits and may have some potentially negative impacts. Therefore, it is difficult to plan for future health information technologies. This study aimed to investigate the key and non-key health information technologies which could be considered for the future strategy development in Iran.

Methods: In this study, experts and policymakers in the field of health information technology were invited to take part in a qualitative study. Purposive sampling was used to select the most informant people, and 13 interviews were conducted. The method of framework analysis was used to analyze data.

Results: The four main themes emerged from data analysis were 1) immediate, cheap, stable, and secure access to the health records of the society, 2) equitable access to health care resources and services, 3) knowledge management in healthcare services, and 4) governmental/central electronic services for the health system. To cover the mentioned areas, a number of key and non-key technologies were discussed by the interviewees.

Conclusion: In this study, a number of key and non-key health information technologies were recognized. While the findings can help policymakers to pay more attention to the key technologies to improve healthcare delivery, these technologies need to be prioritized in terms of their importance for the country.

Keywords: Health information technology, Information technology, Foresight, Qualitative research, Decision making, Policymaker

Conflicts of Interest: None declared

Funding: Iran University of Medical Sciences (IUMS/SHMIS_93/115)

\section{*This work has been published under CC BY-NC-SA 1.0 license. \\ Copyright $\subseteq$ Iran University of Medical Sciences}

Cite this article as: Hemmat M, Ayatollahi H, Maleki M, Saghafi F. Health information technologies in Iran: Opportunities for development. Med J Islam Repub Iran. 2019 (30 Sep);33:103. https://doi.org/10.47176/mjiri.33.103

\section{Introduction}

Health information technology (HIT) includes a variety of technologies that are used to collect, store, or disseminate patient's data (1). Some of the advantages of health information technology (HIT) are improving the quality of health care, reducing healthcare costs $(2,3)$, increasing the accessibility of health information, and reducing medical errors (4-6). Nevertheless, the risk of the potential negative impacts should not be underestimated (7), and it is

\section{Corresponding author:Dr Haleh Ayatollahi, ayatollahi.h@iums.ac.ir}

1. Social Determinants of Health Research Center, Saveh University of Medical Sciences, Saveh, Iran

2. Health Management and Economics Research Center, Iran University of Medical Sciences, Tehran, Iran

3. School of Health Management and Information Sciences, Iran University of Medical Sciences, Tehran, Iran

4. School of Management, University of Tehran, Tehran, Iran important to be able to plan for the future health information technology carefully, while there is no clear picture of the years ahead $(8,9)$. To achieve this, conducting a foresight study has been recommended (10-12). Foresight is "a systematic process with a long-term vision in scientific, technological, economic, and social areas which aims to determine strategic research areas and to provide a basis for the emergence of new technologies with more

$\uparrow$ What is "already known" in this topic:

Technology foresight identifies key technologies. Although this type of research helps to explore the future of technology in a country, few studies have been conducted in developing countries to identify the key and non-key health information technologies.

\section{$\rightarrow$ What this article adds:}

According to the results, the experts believed that a number of key health information technologies should be considered for the next decade. As a result, policy-makers need to prioritize allocating financial and physical resources to develop the needed health information technologies for the country. 
benefits for the community" (13-15).

Among different types of foresight studies, technology foresight helps to identify the key or critical technology issues of a country which should be considered for the desired future $(16,17)$. To conduct foresight studies, different methods, such as Delphi technique, expert panel, literature review, scenario building, and key/critical technologies are used (18-20). Although conducting a foresight study has been suggested to explore the future of HIT $(21,22)$, few studies have been conducted in developing countries to identify the key and non-key health information technologies $(23,24)$. In Iran, a study was conducted between 2007 and 2010 as part of a comprehensive scientific health map; however, the key technologies were not discussed in detail (25).

Another study was a pilot foresight study to identify the most appropriate technologies for Iran 2025 (PAMFA 2025). In this study, all future technologies for the country along with the possible health information technologies were identified; however, the main focus was not on the health information technologies (20). Therefore, the current study aimed to investigate the key and non-key health information technologies which could be considered for the future strategy development in Iran.

\section{Methods}

This qualitative study was conducted in 2016 . The purposive sampling method was used to invite the potential participants who had been previously involved in the development of a comprehensive scientific plan for the country in 2010 and 2011 ( $\mathrm{N}=20)$. In total, 13 in-depth semi-structured interviews were conducted with the experts.
Before conducting the interviews, a topic guide containing some general questions was developed based on the literature review and the comprehensive scientific health map of Iran $(25,26)$. The interview guide included questions about the key and the non-key health information technologies to improve the accessibility of the individuals' health records across the country, to improve health equity, to support and manage medical sciences, and to improve electronic and e-health services. The interviews were recorded and transcribed verbatim. To analyze data, framework analysis was used. Framework analysis is used in the applied policy research in order to answer specific questions and includes five main steps: familiarization, identifying a thematic framework, indexing, charting, and mapping and interpretation $(27,28)$. In the current study, MAXQDA software, version 10.0 was used to store, organize, and analyze relationships, concepts, contradictions, and opinions. The validity of the findings was examined by sending a summary of the results to the interviewees to review and confirm the themes.

\section{Results}

A total of 13 interviews were conducted which lasted for an average of 44 minutes. Most of the participants were men $(n=12,92.3 \%)$ and the highest frequency was related to the age group of 50-59 $(\mathrm{n}=7,53.8 \%)$. In terms of education, most of the participants $(n=8,61.5 \%)$ had a Ph.D. degree, and in terms of the work experience in HIT, the highest frequency was related to $6-10$ years $(n=6$, 46.2\%). After data analysis, four main themes and related key and non-key health information technologies were identified (Table 1).

The first theme emerged from the data analysis was

Table 1. Key and non-key health information technologies

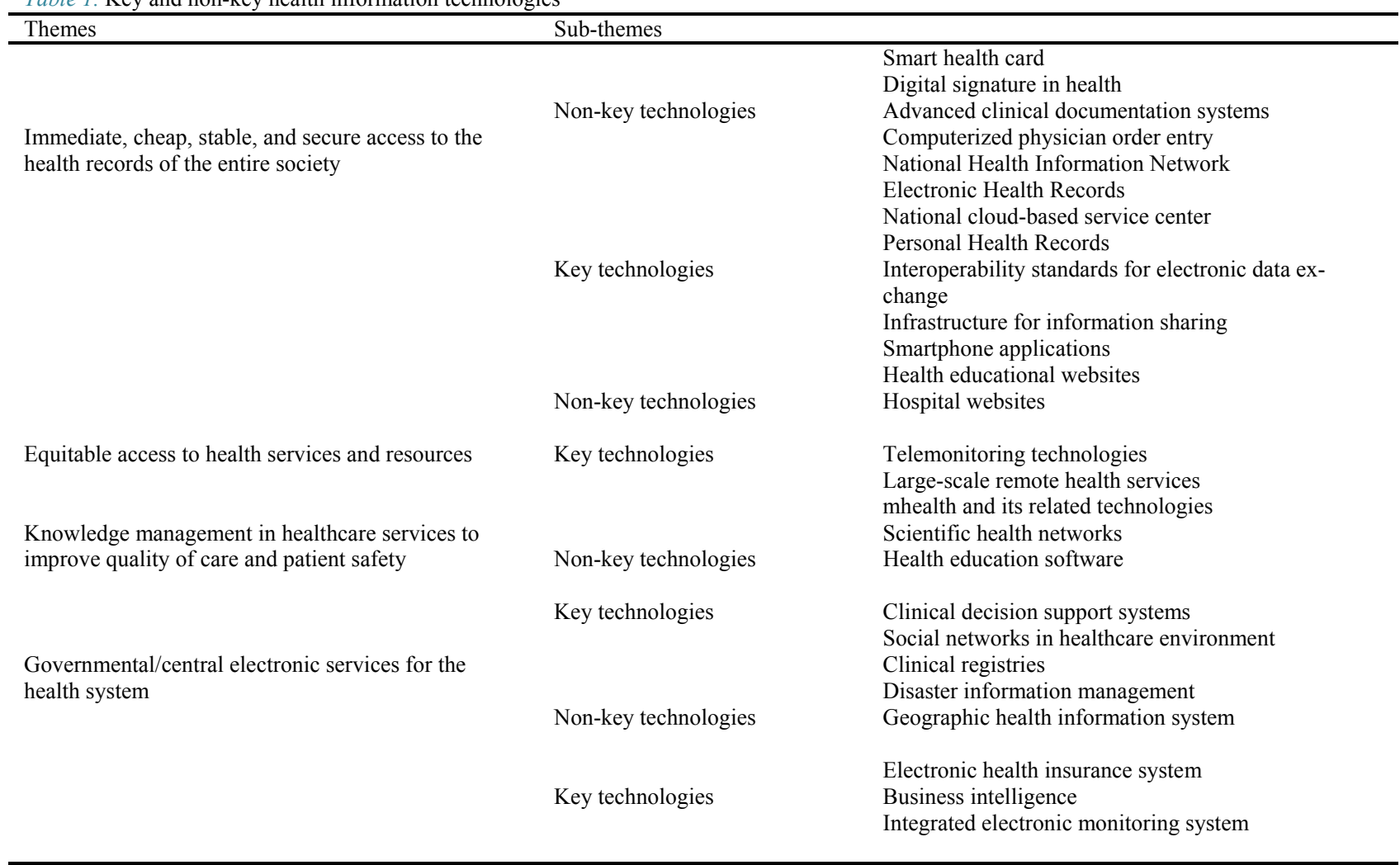


immediate, cheap, stable, and secure access to the health records of the entire society. The interviewees agreed that some technologies, such as a smart health card, a digital signature, advanced clinical documentation systems, and computerized physician order entry systems are important for the country; however, they can be considered as nonkey technologies. For example, one of the interviewees noted:

"We do have computerized physician order entry systems in the country; however, the use of this system is not ubiquitous, it is necessary to have it along with electronic health records" (M-12).

The key technologies which were found to be necessary for the country were a national health information network, an integrated electronic health records (EHR), a national cloud-based service center for integrating health data, personal health records, interoperability standards for electronic data exchange, and an infrastructure for information sharing across the public and private health care organizations. In this regard, one of the interviewees indicated: "PHR is a fundamental issue that seeks proper planning. ... The information is generated by the patient and that can have positive effects." (M-6)

Theme two was related to equitable access to health care resources and services. To achieve this goal, the nonkey technologies, such as smartphone applications, health education and hospital websites were suggested. According to one of the interviewees: "smartphone applications can be used in many different fields to facilitate the accessibility of educational information, ... such a technology can save time for people." (M-12)

However, most interviewees believed that telemonitoring technologies, such as sensors and biometric, largescale remote healthcare services, and mhealth and its related technologies are the key technologies to gain equitable access to health care resources. One of the participants noted:

"Generally, telehealth services can be regarded as a key technology, ... we need to plan for this technology, and we have to use it in the future." (M-5)

Theme three was about knowledge management in healthcare services. According to the interviewees, the non-key technologies were scientific health networks, and health education software, and the key technologies were clinical decision support systems as well as social networks in the healthcare environment.

Creating social networks in the healthcare environment was another key technology which was mentioned by a number of interviewees. One of the interviewees indicated "although several years have passed since the advent of this technology, we could not properly use it." (M-1).

Theme four was related to the importance of governmental/central electronic services for the health system. The participants thought that clinical registries, disaster information management, and geographic health information systems are important, but they are among the non-key technologies. The key technologies included an electronic health insurance system, business intelligence to collect and analyze data, and an integrated electronic monitoring system to evaluate healthcare services. For example, regarding business intelligence, one of the interviewees believed that "structured and unstructured data exist in a variety of health information systems and data analysis can be improved through business intelligence". (M-1)

Concerning the importance of an integrated electronic system for monitoring and evaluating healthcare services, it was expected that using this system helps to improve healthcare quality and staff performance. For example, one of the interviewees stated: "Although we do have a monitoring and evaluation system, having an integrated electronic monitoring system, especially for science and technology can be considered a key technology". (M-11)

\section{Discussion}

The present study aimed to investigate the key and nonkey health information technologies which could be considered for the future strategy development in Iran. As instant, cheap, stable, and secure access to the heath records of the entire society is an important objective for the country, a number of key technologies, such as NHIN, an integrated EHR, PHR, and a national cloud-based service center for integrating health data were suggested. Similarly, in Valle et al.'s study, NHIN was considered a key technology (29). The importance of implementing an integrated EHR has been addressed in PAMFA project, too, and it was expected to get access to EHR in Iran by 2025 (26). Moreover, the importance of this technology has also been highlighted in the comprehensive scientific health map of Iran (25). Similarly, the development of a national cloud-based service center for integrating health data $(30$, 31 ) and PHR have been considered two key technologies to improve the quality of care $(24,32)$.

The equitable access to health care resources and services, could be achieved by the development of patient telemonitoring technologies, such as sensors and biometrics. These technologies are among the most influential technologies in the next decade (8). The results showed that the development of telehealth and mhealth services needs to receive more attention in the future. Although, in another study, mobile technology has been recognized as a key technology for the country; the use of mhealth technologies needs further attention (33).

According to the results, knowledge-based and clinical decision support systems and social networks were other key health information technologies for the country. Although the importance of developing these systems has been emphasized in the previous plans, it seems that no significant progress has been made in this area. The importance of using clinical decision support systems has also been addressed in other studies $(23,8)$.

Other key health information technologies for the country included the governmental/central electronic services, such as electronic health insurance system and an integrated electronic system to monitor and evaluate healthcare services. Similarly, Davari et al. discussed the necessity of using these technologies for the health system (34). 


\section{Limitations}

The current study had some limitations. Firstly, a limited number of experts agreed to be interviewed. However, the researchers believed that these participants were the key informants, and their opinions and experiences were helpful to recognize the key health information technologies for the country. Secondly, although the key and nonkey health information technologies were identified in this research, the level of importance among key technologies is not clear and needs to be investigated by using different research methods.

\section{Conclusion}

In this study, the experts' opinions about the key and non-key health information technologies for the country were presented. The results can be useful for policymakers to focus on the key health information technologies and to prioritize allocating financial and physical resources to develop the needed health information technologies in the country. The use of multiple methods is suggested to increase the credibility and validity of the results and to rank the top 10 key health information technologies.

\section{Acknowledgments}

This paper was derived from a $\mathrm{PhD}$ thesis which was funded and supported by Iran University of Medical Sciences (IUMS/SHMIS_93/115).

\section{Conflict of Interests}

The authors declare that they have no competing interests.

\section{References}

1. Sittig DF, editor. Electronic health records: Challenges in design and implementation: Florida: Apple Academic Press; 2014.

2. Desalvo KB. Federal health IT strategic plan 2015-2020. Washington: Office of the National Coordinator for Health Information Technology (ONC), 2014.

3. Ahlan AR, Ahmad BIE. User acceptance of health information technology (HIT) in developing countries: a conceptual model. Proc Technol. 2014;16:1287-96.

4. Blackwell G, Blackwell G. The future of IT in healthcare. Inform Health Soc Care. 2008;33(4):211-326.

5. Ehrenfeld JM, Cannesson M. Monitoring technologies in acute care environments: a comprehensive guide to patient monitoring technology. New York: Springer; 2014.

6. Rothman B, Leonard JC, Vigoda MM. Future of electronic health records: implications for decision support. Mt Sinai J Med. 2012;79(6):757-68.

7. Ayatollahi H, Bath PA, Goodacre S. IT in the emergency department-what is the impact of technology? In: Azevedo L LA, editor. Proceedings of International Conference on Health Informatics (HealthInf 2009); 14-17 January; Porto: Portugal, 2009. p. 454-7.

8. Cresswell KM, Sheikh A. Key global developments in health information technology. J Roy Soc Med. 2016;109(8):299-302.

9. Wyatt JC, Sullivan F. eHealth and the future: promise or peril? $\mathrm{Br}$ Med J. 2005;331(7529):1391-3.

10. Behkami NA, Daim TU. Research forecasting for health information technology (HIT), using technology intelligence. Technol Forecast Soc Change. 2012;79(3):498-508

11. Turley JP. The future of health care informatics education. In: Englebardt SP, Nelson R, editors. Health care informatics: an interdisciplinary approach. Missouri: Mosby; 2002. p. 479-503.

12. Staggers N, Nelson R, Jones DE. Future Directions and Future
Research in Health Informatics. In: Nelson R, Staggers N, editors Health informatics: an interprofessional approach. Missouri: Mosby; 2013. p. 494-508.

13. Martin B. Technology foresight in a rapidly globalizing economy. Regional conference on technology foresight for CEE and NIS countries; 2001, 4-5 April 2001; Vienna, Austria.

14. Hemmat M, Ayatollahi H, Maleki M, Saghafi F. Future research in health information technology: a review. Perspect Health Inf Manag. 2017, 14: 1b.

15. Poteralska B, Sacio-Szymańska A. Evaluation of technology foresight projects. Eur J Futures Res. 2014;2(1):1-9.

16. Chen H, Wakeland W, Yu J. A two-stage technology foresight model with system dynamics simulation and its application in the Chinese ICT industry. Technol Forecast Soc Change. 2012;79(7):1254-67.

17. Chan L, Daim T. Exploring the impact of technology foresight studies on innovation: Case of BRIC countries. Futures. 2012;44(6):618-30.

18. UNIDO. UNIDO technology foresight manual: organization and methods. Vienna: United Nations Industrial Development Organization; 2005.

19. European Foresight Platform (EFP) consortium. Key technology study. [Internet] 2010 [Cited 02 Mar 2018] Available from: http://www.foresight-platform.eu/community/forlearn/how-to-doforesight/methods/expert-panels/key-technology-study/.

20. Joint Research Commision. Critical \& key technology study. [Internet] 2007 [Cited 05 Mar 2018] Available from: http://forlearn.jrc.ec.europa.eu/guide/4 methodology/meth criticaltechnology.htm

21. Englebardt SP, Nelson R. Health care informatics: an interdisciplinary approach. St. Louis: Mosby; 2002.

22. Nelson R, Staggers N. Health informatics: An interprofessional approach. St. Louis: Elsevier Health Sciences; 2013.

23. Turan AH, Palvia PC. Critical information technology issues in Turkish healthcare. Inform Manag. 2014;51(1):57-68.

24. Palvia $\mathrm{P}$, Lowe $\mathrm{KB}$, Nemati $\mathrm{H}$, Jacks T. Information technology issues in healthcare: hospital CEO and CIO perspectives. Comm Assoc Inform Syst. 2012;30(1):293-312.

25. Riazi H, Abedian S. Health system map of Iran 1404: health information technology. Tehran: Statistics and Information Technology Office, Ministry of Health and Medical Education; 2011.

26. Naderimanesh M, Shammaee A, Ghadiri R, Nazemi A. Information technology foresight: Iran 2025. Tehran: National Research Institute for Science Policy (NRISP); 2009

27. Ritchie J, Spencer L. Qualitative data analysis for applied policy research. In: Huberman $M$, Miles MB, editors. The qualitative researcher's companion. London: Sage publications; 2002. p. 305-29.

28. Srivastava A, Thomson SB. Framework analysis: a qualitative methodology for applied policy research. J Publ Admin Govern. 2009;4(2):72-9.

29. Valle J, Gomes C, Godby T, Coustasse A. The feasibility of the nationwide health information network. Health Care Manag. 2016;35(2):103-12.

30. Goli-Malekabadi Z, Sargolzaei-Javan M, Akbari MK. An effective model for store and retrieve big health data in cloud computing. Comput Meth Programs Biomed. 2016;132:75-82.

31. Weng SJ, Lai LS, Gotcher D, Wu HH, Xu YY, Yang CW. Cloud image data center for healthcare network in Taiwan. J Med Syst. 2016;40(89):1-11.

32. Zhang L, Wu Q, Mu Y, Zhang J. Privacy-preserving and secure sharing of PHR in the cloud. J Med Syst. 2016;40(267):1-13.

33. Zare Mirakabad A, Niazi I, Salehi S. Foresight of key technologies in Iran ICT industry: identification of business models. Industrial Management Vision. 2012;4:107-30.

34. Davari M, Haycox A, Walley T. The Iranian health insurance system; past experiences, present challenges and future strategies. Iran J Public Health. 2012;41(9):1-9. 